\title{
DERECHOS HUMANOS Y DERECHOS FUNDAMENTALES. ALGUNOS COMENTARIOS DOCTRINALES
}

\author{
Jennifer Batista Torres \\ Profesora de Derecho Laboral y de Seguridad Social, \\ Facultad de Derecho Universidad de La Habana, Cuba ${ }^{1}$
}

\begin{abstract}
El presente artículo tiene como objetivo fundamental el de abordar cuestiones doctrinales sobre los derechos humanos y los derechos fundamentales. Para ello realiza un análisis histórico de los elementos generales sobre los derechos humanos, para luego explicar la relación con los derechos fundamentales. De esta forma, se realizan valoraciones para determinar las características, clasificación y elementos de esta figura, defendiendo su naturaleza de derechos subjetivos.
\end{abstract}

The main objective of this article is to address doctrinal questions about human rights and fundamental rights. To do this, it carries out a historical analysis of the general elements on human rights, to then explain the relationship with fundamental rights. In this way, assessments are made to determine the characteristics, classification and elements of this figure, defending their nature of subjective rights.

Title: Human rights and fundamental rights. Some doctrinal comments

Palabras clave: derechos humanos, derechos fundamentales, características, clasificación y elementos

Key words: human rights, fundamental rights, characteristics, classification, elements

IUSLabor 2/2018, ISSN 1699-2938, p. 186-213

10.31009/IUSLabor.2018.i02.05

\section{Sumario}

1. Derechos humanos: planteamiento histórico

2. Derechos fundamentales: caracterización teórica

2.1. Características y clasificación de los derechos fundamentales

2.2. Elementos de los derechos fundamentales

3. Bibliografía

\footnotetext{
${ }^{1}$ Licenciada en Derecho. Máster en Derecho Constitucional y Derecho Administrativo. Estudiante de Doctorado.
} 


\section{Derechos humanos: planteamiento histórico}

La consagración de los denominados «derechos humanos» es un hecho consumado en la actualidad. Y es que, sin lugar a dudas, los derechos humanos son el resultado de un largo proceso de evolución del hombre en lo social, lo político y lo jurídico. Pero, sobre todo, estos derechos han significado las mayores conquistas para el hombre en su relación primero frente «al poder monárquico» y con el Estado, así como en las relaciones entre los propios individuos. Los derechos humanos poseen una trascendencia tal que se conciben ${ }^{2}$ como prerrogativas que poseen todos los seres humanos, sin importar su condición.

Precisamente por esto es que se hace necesario iniciar este estudio por identificar algunas cuestiones que se pudieran considerar como punto de partida para dar cumplimiento a los propósitos de esta investigación. En primer lugar, porque los «derechos humanos» son uno de los antecedentes de los derechos fundamentales. El proceso de formación de los derechos humanos influyó notablemente en la concepción actual de tales derechos. Derivado de esto, aún se identifican a los derechos humanos con los derechos fundamentales ${ }^{3}$, y en algunos casos, solamente se diferencian por el ámbito de protección ${ }^{4}$. Otra razón que justifica dedicar un espacio para abordar algunas cuestiones medulares sobre los derechos humanos es que el trabajo es, ante todo, un derecho humano y un derecho fundamental. Solo desentrañar el íter evolutivo de ambas categorías jurídicas y las circunstancias en las que surgieron, significará una cuestión para entender los elementos que configuran hoy día al trabajo como derecho.

Se puede ubicar el surgimiento de los derechos humanos en la etapa de transición entre el feudalismo y el capitalismo. Sus antecedentes datan de aproximadamente el siglo XVIII en medio del pensamiento liberal revolucionario de la época ${ }^{5}$. Así, se consagraron como producto de las revoluciones burguesas y como parte de la juridización de los postulados en las Constituciones de fines del siglo XVIII y principios

\footnotetext{
${ }^{2}$ Cfr. Bernal Ballesteros, M.J., y De PAZ GonzÁlez, I. (Coordinadores): Fundamentos axiológicos de los derechos humanos, 1ra ed., Comisión de los Derechos Humanos del Estado de México, México 2016, p. 9.

${ }^{3}$ Vid. Aguilar Cavallo, G., "Derechos fundamentales- Derechos humanos. ¿Una distinción válida en el siglo XXI?" en Boletín Mexicano de Derecho Comparado, Nueva Serie, Año XLIII, No. 127, eneroabril, México, 2010, pp. 21 y ss.

${ }^{4}$ Vid. CARPIZO. J.,: "Los derechos humanos: naturaleza, denominación y características" en Revista Cuestiones Constitucionales, No. 25, julio- diciembre, México, 2011, p. 7

${ }^{5} \mathrm{Vid}$. BASTIDA, Francisco J. et alias: Teoría general de los derechos fundamentales en la Constitución española de 1978, Editorial Tecnos, Madrid, 2004, p. 13.
} 
del $\mathrm{XIX}^{6}$. Y es que los derechos humanos han pasado por varios periodos para su formulación actual. Una primera etapa, que se pudiera denominar «estamental», tuvo como principal hito la Carta Magna inglesa de 1215. Tiempo después, fuera de esta etapa, son antecedentes también la Ley de habeas corpus de 1679 y el Bill of Rights de $1689^{7}$, en las cuales se reconocían un conjunto de prerrogativas a los señores frente al monarca. De esta manera se ponía un coto a los poderes ilimitados de la Corona en beneficio de sus súbditos. Con dichos documentos se inicia el desarrollo de la idea de derechos civiles.

Un segundo momento fue con las cartas y declaraciones de derechos, producto de la ideología liberal, del iusnaturalismo y de la influencia de la Ilustración y el enciclopedismo francés $^{8}$. De esta etapa se consideran antecedentes la Declaración de Independencia norteamericana de 1776, la Declaración de Derechos de Virginia del propio año y la Carta de Derechos de 1789 de la Constitución norteamericana. Igualmente, la DDHC y la Declaración de los Derechos de la Mujer y la Ciudadana de $1791^{9}$. Todas ellas, son muestra del abandono del poder monárquico y el surgimiento del Estado constitucional como ente que organiza la sociedad y que debe respetar la libertad de las personas. En esta etapa entonces, no solamente existían derechos de las personas frente al poder, sino comienzan a surgir los derechos de participación política. Pero la sociedad continuó su desarrollo y a finales del siglo XIX las relaciones sociales volvieron a mutar, debido a las pésimas condiciones de vida y de trabajo de los obreros, produciéndose luchas, obreras demandándose el reconocimiento de nuevos derechos que permitieran dar solución a ciertos problemas sociales a través de la intervención del Estado. En este sentido tuvo especial trascendencia la obra de Karl MARX y Federico ENGELS ${ }^{10}$.

De resultas, a principios del siglo XX se produce otro proceso de consagración de derechos humanos, donde finalmente pasan a tener una protección constitucional nuevos derechos «los derechos económicos, sociales y culturales». Así, la principal carta constitucional exponente de esta etapa es la Constitución de Querétaro, México, de 1917 que, por primera vez, reconoce un conjunto de derechos a la nueva clase social, los

\footnotetext{
${ }^{6}$ Vid. D'Estefano Pisani, M. A., Fundamentos del Derecho Internacional Público, T., I, Facultad de Derecho, La Habana, S/Año, p. 263.

${ }^{7}$ Vid. CAStilHo, R., Direitos Humanos, Editora Saraiva, São Paulo, 2011, pp.35 y ss.

${ }^{8}$ Vid. Konder Comparato, F., A Afirmação histórica dos direitos humanos, $7 \mathrm{ma}$ Ed., Editorial Saraiva, São Paulo, 2010, p.67.

9 Vid. Soberanes FernándeZ, J. L., Sobre el origen de las Declaraciones de Derechos Humanos, UNAM, México, 2009, pp. 159 y ss.

${ }^{10}$ Cfr. Passim MarX, K. y Engels, F. Manifiesto del Partido Comunista, Editorial de Ciencias Sociales, La Habana,1975; MARX, K., "Trabajo asalariado y capital" en Neue Rheniscbe Zeitung, núm. 266, de abril 7 de 1849; MARX, K.., El Capital, Tomo I, Editorial Ciencias Sociales, La Habana, 1973.
} 
trabajadores, colocando en manos del Estado la obligación de contribuir al efectivo ejercicio de esto derechos ${ }^{11}$. Igualmente, se encuentra como hito la Constitución alemana de Weimar en 1919, que fuera la primera en establecer un sistema de seguros sociales que protegiera a los trabajadores frente a diferentes situaciones en el marco del trabajo $^{12}$. Por último, un papel importante lo tuvieron las Constituciones soviéticas. Si bien no fue hasta la Constitución de $1936^{13}$ que el trabajo fue reconocido como un derecho, desde la Constitución de $1918^{14}$ se establecen elementos que caracterizan al nuevo Estado que es de trabajadores. Así, las Constituciones de 1923 y 1925 implementan un servicio de inspección obrera y campesina y reconocen al trabajo como un deber; respectivamente ${ }^{15}$.

Finalmente, y tras las dos guerras mundiales, los derechos humanos trascendieron al ámbito internacional y con ello se produjo su reafirmación histórica ${ }^{16}$. También, durante esta etapa de solidificación de los derechos humanos, se les comienza a diferenciar «según el momento de su nacimiento y teniendo en cuenta su contenido ${ }^{17}{ }^{1}$ en derechos civiles, políticos y económicos, sociales y culturales. En este sentido, se encuentran la DUDH, los PIDCP y PIDESC, ambos de 1966; así como la Convención Americana de Derechos Humanos de 1969. Todos ellos promueven su protección y figuran como un indicador de aquellos derechos que poseen los seres humanos con independencia de su relación con un Estado determinado.

A este mismo íter histórico respondió la construcción y evolución de la definición de los derechos humanos. Cada una respondió a un modelo filosófico determinado. Así se

${ }^{11}$ Cfr. Artículos 1, 2, 3 y 123 de la Constitución mexicana de 1917 en Diario Oficial, No. 30, Tomo V, 4ta época, 5 de febrero de 1917, México disponible en http://www.diputados.gob.mx/LeyesBiblio/ref/cpeum/CPEUM_orig_05feb1917_ima.pdf-, consultado el 14 de diciembre de 2016.

12 Cfr. Artículos 157 y ss. Y 161 de la Constitución de Weimar en https://www.google.com.cu/url?sa=t\&rct=j\&q=\&esrc=s\&source=web\&cd=1\&cad=rja\&uact=8\&ved=0ah UKEwiU1ebhgPTQAhVDzFQKHfixBEgQFggYMAA\&url=http\%3A\%2F\%2Fwww.unav.es\%2Fconstitu cional\%2FMateriales\%2FConstitucion\%2520de\%2520Weimar\%2520(1919).pdf\&usg=AFQjCNG5Xrxfl DAWDVEH8pxItZ9CfRRE6w\&bvm=bv.141536425,bs.2,d.eWE, consultado el 14 de febrero de 2016.

${ }^{13}$ Cfr. Artículo 118 de la Constitución soviética de 25 de noviembre de 1936 en LINARES QUINTANA, Segundo V.: Derecho Constitucional soviético. Estudio y texto de las Constituciones de la URSS, Biblioteca Jurídica, Vol. 30, Editorial Claridad, Buenos Aires, S/Año.

${ }^{14}$ Vid. Artículo 1 y 3 de la Constitución soviética de 1918 en Linares Quintana, S. V. Derecho... op. cit.

${ }^{15}$ Cfr. Artículo 37 de la Constitución soviética de 6 de julio de 1923 y artículo 9 de la Constitución soviética de 11 de mayo de 1925 en Linares Quintana, Segundo V.: Derecho... op. cit.

${ }^{16}$ Vid. Passim CaSAdo Filho, N., Direitos humanos e fundamentais, Editora Saraiva, São Paulo, 2012; DE CARVAlho Ramos, André: Teoria geral dos direitos humanos na ordem internacional, Editora Saraiva, São Paulo, 2012.

${ }^{17}$ Cfr. DUDH, PIDCP, PIDESC. 
tienen dos grandes tendencias para explicar la conceptualización de los derechos humanos: la iusnaturalista ${ }^{18}$ y la iuspositivista ${ }^{19}$.

Según el primer modelo filosófico, se parte de la existencia previa de un derecho natural que se reconduce a la propia naturaleza humana. De esta nacen libertades para el hombre, las cuales le son inherentes por su condición de persona y que solo están limitados por aquellos que permitan a otros miembros de la sociedad disfrutar de los $\operatorname{mismos}^{20}$. Con esta tendencia se alude a que los derechos humanos están presentes, son anteriores a cualquier ordenamiento jurídico.

A contrario sensu, el modelo positivista basa la existencia de los derechos humanos en su reconocimiento en norma jurídica, trayendo causa de la decisión que tome un órgano estatal determinado. Siendo así, los derechos se crean, no se declaran, por lo cual se hace indispensable determinar aquellos fenómenos sociales que deban ser considerados libertades o derechos. Derivado de ello se requiere, además, determinar la titularidad, el contenido y los límites de cada derecho, y se introduce también la idea de la necesidad de garantizarlos ${ }^{21}$, como elemento que completa su formulación.

Lo cierto es que los derechos humanos son un conjunto de prerrogativas que le son inherentes a las personas por su condición de tales. Estas libertades podrán ser ejercidas frente al Estado, quien está en la obligación de respetarlas, promoverlas y garantizarlas. Tales prerrogativas son reconocidas en el ámbito internacional ${ }^{22}$ como «derechos humanos» y derivan ante todo, de la noción de dignidad de las personas frente al Estado $^{23}$. Tal es así que ALEXY ${ }^{24}$ plantea que los derechos humanos representan el núcleo de la justicia.

\footnotetext{
${ }^{18}$ Sobre este tema, Cfr. CASTÁn TOBEÑ̃As, J., Los derechos humanos, Editorial Reus, Madrid, 1978; Monroy CABRA, M. G., Los derechos humanos, Editorial Temis, Bogotá, 1980.

19 C fr. Peces Barba Martínez, G., Derechos y derechos fundamentales, Centro de Estudios Constitucionales, Madrid, 1993 y PÉREZ LuÑo, A. E., Derechos Humanos, Estado de Derecho y Constitución, 5ta Ed., Editorial Tecnos, Madrid, 1995.

${ }^{20}$ Vid. Artículo 4 de la DDHC, disponible en http://avalon.law.yale.edu/18th_century/rightsof.asp, consultado el 9 de octubre de 2015.

${ }^{21}$ Vid. FerRaJoli, L., "Sobre los derechos fundamentales" en Teoría del Neoconstitucionalismo. Ensayos escogidos, Edición de Miguel CARBOnell, Instituto de Investigaciones Jurídicas, UNAM, Editorial Trotta, Madrid, 2007, p. 72.

${ }^{22}$ Vid. DUDH.

${ }^{23}$ Vid. NikKen, P., "El concepto de derechos humanos" en Estudios Básicos de Derechos Humanos, T. I, CERDAS CRuz R., y NieTo LoAiza R., IIDH, San José, 1994, p. 15.

${ }^{24}$ Cfr. AleXY, R., "Law, morality and the existence of human rights" en Ratio Iuris, Vol. 25, No. 1, marzo de 2012, p. 9.
} 
Dichos derechos se pueden definir entonces como el conjunto de facultades que, en cada momento histórico, concretan las exigencias de libertad, dignidad e igualdad humanas, las cuales deben ser reconocidas positivamente por los ordenamientos jurídicos internos e internacionales ${ }^{25}$. Son derechos que pertenecen a la persona humana independientemente de estas, que protegen los diferentes ámbitos en los que interactúa, distinguiéndose cuatro de ellos esencialmente: vida, libertad, igualdad y seguridad personal $^{26}$. Los «derechos humanos» poseen además un contenido amplio, que incluye un conjunto de derechos que poseen todos los seres humanos sin distinción por su origen, color, sexo, idioma, religión u otro ${ }^{27}$. En principio ${ }^{28}$, son derechos humanos todos los atributos que posee la persona humana como ser físico, psíquico y social. En fin, suponen la preexistencia de cualidades para los seres humanos que pueden exigir frente al Estado.

Derivado de esto, los derechos humanos tienen un conjunto de características. Varios autores explican sus criterios al respecto, sin embargo, todos parecen coincidir en que estos derechos poseen una característica esencial: son universales. ALEXY ${ }^{29}$ por ejemplo, plantea que las propiedades que caracterizan a los derechos fundamentales son cinco: universalidad, fundamentalidad, abstracción, moralidad y prioridad. Para NIKKEN $^{30}$ por su parte, los derechos humanos se caracterizan por ser, también transnacionales, irreversibles y progresivos. Otros autores coinciden en que sus características son la imprescriptibilidad, la inalienabilidad, la irrenunciabilidad, la inviolabilidad, la efectividad, la interdependencia y la complementariedad ${ }^{31}$.

Lo cierto es que los derechos humanos los poseen todos los hombres y mujeres por el simple hecho de ser tales, son indisponibles -en sentido amplio- por el Estado o cualquier persona, deben ser respetados por todos y trascienden las fronteras geográficas y a la clásica relación Estado-individuo e individuo-individuo.

\footnotetext{
${ }^{25}$ Vid. Pérez LuÑo, A. E., Derechos Humanos. Estado de Derecho y Constitución, 7 ma Ed., Editorial Tecnos, Madrid, 2001, p. 48.

${ }^{26}$ Vid. CAStiLHO, R., Direitos humanos, Editora Saraiva, São Paulo, 2011, p. 12.

${ }^{27}$ Cfr. Artículo 2.1 de la DUDH.

${ }^{28}$ Vid. Russo, E.A., Derechos humanos y garantías. El derecho al mañana, 1ra Ed., 1ra reimpresión, Editorial Universitaria de Buenos Aires, Buenos Aires, 2001, p. 36

${ }^{29}$ Vid. ALEXY, R., "The existence of human rights" in Law, Science, Technology, Frankfurt am Main, 2011, pp. 10 y ss.

${ }^{30}$ Vid. NIKKEN, P., "El concepto... op. cit., pp. 25 y ss.

${ }^{31}$ Cfr. García BeCERra, J. A., Teoría de los derechos humanos, 1ra Ed., Universidad Autónoma de Sinaloa, México, 1991, pp. 20 y ss.; PACHECO G., Máximo: "Los derechos fundamentales de la persona humana" en Estudios básicos de derechos humanos, T.: II, Kenneth Anderson et alias, IIDH, San José, 1995, p. 72; Rebello Pinho, R. C., Teoria Geral da Constituição e Direitos Fundamentais, Vol. 17, $11^{\text {a }}$ edição, Editora Saraiva, São Paulo, 2011, p. 97.
} 


\section{Derechos fundamentales: caracterización teórica}

Ligado a la idea de derechos humanos se encuentra la de derechos fundamentales ${ }^{32}$. Ambas denominaciones fueron utilizadas indistintamente por mucho tiempo ${ }^{33}$. De igual manera se les denominó derechos subjetivos, derechos subjetivos públicos y derechos individuales ${ }^{34}$.

La protección de los «derechos humanos» está reservada en el ámbito interno de los Estados mediante las declaraciones de derechos ${ }^{35}$, como derechos fundamentales. Tras su constitucionalización, los derechos humanos pasaron a tener un ámbito de protección dual. Es decir, los derechos humanos lograron ser consagrados en las Constituciones; sin embargo, los propios textos magnos, ampliaron la gama de derechos, hasta ese momento reconocidos a las personas, en función de su relación como ciudadanos de un Estado. Esto sucedió a inicios del siglo XX, con el denominado «constitucionalismo social» ${ }^{36}$, donde se reconocieron los derechos económicos, sociales y culturales como derechos constitucionales. En el siglo XXI, esta idea se sostiene. Sin embargo, con el reconocimiento del Estado de Derecho, se amplió la gama de derechos en función de las relaciones del hombre como miembro integrante de la sociedad ${ }^{37}$.

De resultas, se reafirmó una ligera diferencia entre ambos tipos de derechos (humanos y fundamentales). Esta distinción puede resumirse en que todos los derechos humanos no son obligatoriamente derechos fundamentales; pero sí todos los derechos fundamentales son derechos humanos ${ }^{38}$. En este sentido, se muestran en planos diferentes por lo cual existen divergencias entre los derechos humanos y los derechos fundamentales. Un primer criterio es en relación a los titulares.

De los derechos humanos son titulares todas las personas sin atender a ninguna condición especial, de los derechos fundamentales solamente los ciudadanos en su

\footnotetext{
${ }^{32}$ Cfr. Ramos Tavares, A., Curso de Direito Constitucional, 12 Ed., Editorial Saraiva, São Paulo, 2014, pp. 335 y ss.

${ }^{33}$ Cfr. PACHeCO G., M., "Los derechos... op. cit., p.67.

${ }^{34}$ Cfr.Da Cunha Júnior, D., Curso de direito Constitucional, $5^{\text {a }}$ edição, Editora Juspodium, SalvadorBahia, 2011, pp. 577 y ss.

${ }^{35}$ Vid. FiX- Zamudio, H., "La evolución del derecho internacional de los derechos humanos en las Constituciones latinoamericanas" en Estudios Básicos...op. cit., p. 51.

36 Vid. ARANGO, R., Constitucionalismo social latinoamericano disponible en http://www.miguelcarbonell.com/artman/uploads/1/constitucionalismo_social.pdf, consultado el 5 de marzo de 2018.

37 Vid. Hernández Martínez, M. del P., Constitución y derechos fundamentales, disponible en http://archivos.juridicas.unam.mx/www/bjv/libros/7/3447/15.pdf,consultado el 19 de febrero de 2018.

${ }^{38}$ Vid. Rubio Llorente, F., La forma del poder. Estudios sobre la Constitución, Vol. III, 3ra Ed., Centro de Estudios políticos y Constitucionales, Madrid, 2012, p. 1089.
} 
condición de tales ${ }^{39}$. En cuanto al contenido, los derechos humanos son meros principios morales o éticos que carecen de toda eficacia jurídica ${ }^{40}$ en tanto no se identifican con aquellos que nacen de normas de derecho positivo.

Al contrario, los derechos fundamentales se consagran en las Constituciones, teniendo reconocidas garantías jurídicas para su defensa ${ }^{41}$. Así, los derechos humanos describen la libertad e igualdad en ciertos ámbitos de la vida que deben garantizarse a todo hombre y mujer, con independencia de un reconocimiento y efectiva protección jurídica en cada ordenamiento en particular. Mientras, los derechos fundamentales son garantías de la libertad e igualdad en ciertos ámbitos de la vida humana, pero en los términos establecidos en un ordenamiento jurídico particular ${ }^{42}$.

Los derechos fundamentales se refieren a ámbitos vitales imprescindibles en los estadios históricos y culturales por los cuales ha pasado el ser humano bajo el Estado Constitucional, con el fin de asegurar el desarrollo de la libertad de la persona. De esta manera, han ganado un espacio sustancial a través de su manifestación jurídico positiva; esencialmente en las Constituciones.

El término «derecho fundamental» (droit fondamentaux) tiene sus orígenes en Francia en 1770 , en el movimiento político y cultural que condujo a la DDHC ${ }^{43}$. Los derechos fundamentales surgieron ante la necesidad de limitar y controlar los abusos eventuales del poder estatal, para proteger la esfera individual del ciudadano de las injerencias indebidas del Estado ${ }^{44}$. La aparición del concepto «derechos fundamentales» se produjo en el tránsito hacia la modernidad ${ }^{45}$, retomando las ideas de dignidad, de libertad y de igualdad del Renacimiento. Son fruto de la desigualdad que se presentó en las sociedades feudales y en el propio nacimiento del Estado Moderno ${ }^{46}$. No solo influyó en su formación el factor social, donde ocurrió una ruptura de la autoridad de la Iglesia

\footnotetext{
${ }^{39}$ Cfr. García SAn Miguel, L., "Qué son los derechos humanos", en Revista Derechos y Libertades, Año 1, No. 2, octubre- marzo, Madrid, 1993, pp. 262 y ss.

${ }^{40}$ Vid. NinO, C.S., "El concepto de derechos humanos" en Ética y Derechos Humanos: un ensayo de fundamentación, Editorial Astrea, Argentina, 1989, p. 23.

${ }^{41}$ Cfr. Bonavides, P., Curso de Direito Constitucional, 31 $1^{\text {a }}$ edição, Malheiros Editores, São Paulo, 2016, p. 575.

${ }^{42}$ Vid. VilLaVerde MenÉNDeZ, I., "Los derechos fundamentales en la historia. Una aproximación a su origen y fundamento" en Estado constitucional, derechos humanos, justicia y vida universitaria, Estudios en homenaje a Jorge Carpizo, T.: V, Vol.2, CARBonell M, FIX- FIERro, H., et alias (Coordinadores), UNAM, México, 2015, pp. 579 y ss.

${ }^{43}$ Vid. PÉREZ LuÑo, A. E., Derechos Humanos... op. cit., p. 30.

${ }^{44}$ Vid. Van Holthe, L., Direito Constitucional, 6ta Ed., Editora Podium, Brasil, 2010, p. 347.

${ }^{45}$ Vid. PeCes- Barba Martínez, G., Derechos... op. cit., p. 326.

${ }^{46}$ Vid. Gicquel, J., y Gicquel, J.E., Droit Constitutionnel et intitutions politiques, 23 Ed., Lextenso éditions, Paris, 2009, p. 89.
} 
impulsando la iniciativa individual, el pluralismo el relativismo y la tolerancia; sino también que aparece el Estado Moderno como forma de poder y comienzan a relacionarse las personas libres, lo que trajo consigo un mayor protagonismo de la persona y nacieron así los derechos individuales ${ }^{47}$, vinculados a los derechos humanos.

Los derechos fundamentales no se han mantenido estáticos. Evolucionaron de acuerdo con cada momento histórico como se explicó. Inicialmente, los derechos fundamentales fueron denominados «libertades» ${ }^{48}$, en lo cual tuvo influencia la Revolución francesa bajo el signo «liberté, egalité et fraternité». En esta etapa, los derechos fueron concebidos en el ámbito de actuación de las relaciones individuales ${ }^{49}$, donde el Estado debía abstenerse de hacer cualquier acción que limitara a los individuos. Igualmente, lo individuos comenzaron a participar en la vida política de la sociedad, aún limitada por el estatus social. En esta época, concomitante con los derechos humanos, se identificaron los derechos individuales y los de participación que se convertirían en derechos civiles y políticos.

Posteriormente, con la aparición del proletariado y la oposición entre éste y la burguesía, favorecida por el laisses faire, laissez passer $^{50}$, se hicieron nuevos reclamos. Tras un largo tiempo de enfrentamiento entre las clases sociales existentes, comenzaron a reconocerse un grupo de derechos de nuevo tipo. Estos derechos respondieron a la situación precaria de los trabajadores y su familia, a la cuestión social, siendo consagrados en las Constituciones sociales del siglo $\mathrm{XX}^{51}$. Finalmente, durante el siglo XX y el XXI, otro conjunto de derechos apareció y se convirtieron en «derechos fundamentales». Es el caso de los denominados «derechos de solidaridad», entre los que se configuran los derechos al desarrollo ${ }^{52}$ y a un medio ambiente sano ${ }^{53}$.

\footnotetext{
${ }^{47}$ Cfr. PeCes- Barba Martínez, G., Derechos... op. cit., pp. 327 y ss.

${ }^{48} C f r$. DDHC disponible en http://avalon.law.yale.edu/18th_century/rightsof.asp, consultado el 9 de octubre de 2015.

${ }^{49}$ Vid. VillaVERDE MenÉNDEZ, I., "Los derechos fundamentales en la historia. Una aproximación a su origen y fundamento" en Estado constitucional... op.cit., p. 583.

${ }^{50}$ Vid. De La Cueva, M., Derecho Mexicano del Trabajo, 3ra Ed., Editorial Porrúa, México, 1949, p. 18.

${ }^{51}$ Cfr. Artículos 3, 4, 5, 123 de la Constitución mexicana de 1917, artículos 120, 157 y 161 de la Constitución alemana de Weimar de 11 de agosto de 1919, preámbulo de la Constitución francesa de 1946, artículos 30, 32, 34, 35 de la Constitución italiana de 1947, artículos 6, 7, 12, 14 de la Constitución alemana de 1949, artículos 42, 43, 47 de la Constitución portuguesa de 1976 y artículos 27, 33, 35, 37 de la Constitución española de 1978.

52 Vid. CANÇADO TRINDADE, A.A., Derechos de Solidaridad disponible en http://www.corteidh.or.cr/tablas/a11993.pdf, consultado el 26 de febrero de 2018.

${ }^{53}$ Vid. Bonavides, P., Curso de Direito Constitucional, 15 Ed. Gráfica Paym, Brasil, 1999, p. 569.
} 
En cuanto a la definición de los derechos fundamentales, se tiene bastante claro el contenido, pero no «qué» es el continente. A ello puede agregarse el hecho de que se les han dado denominaciones diferentes ${ }^{54}$.

La concepción actual más aceptada, es la que FERRAJOLI ${ }^{55}$ presenta. Para este autor, los derechos fundamentales son aquellos derechos subjetivos que corresponden universalmente a todos los seres humanos en cuanto dotados del estatus de personas, de ciudadanos o de personas con capacidad de obrar. En tal sentido, entiéndase por derecho subjetivo cualquier expectativa - positiva o negativa- adscrita a un sujeto por una norma jurídica. Y por estatus, la condición de un sujeto, prevista por una norma jurídica, como presupuesto de su idoneidad para ser titular de situaciones y/o autor de los actos que son ejercicio de estatus ${ }^{56}$. Según esta definición todos los derechos humanos son fundamentales. Por eso se tiende a decir que no forman un sistema cerrado, sino que existen en el ordenamiento jurídico con independencia de su base filosófica o ideológica $^{57}$.

FERRAJOLI también justifica su definición teórica planteando que no son fundamentales solo los derechos adscritos en las Constituciones sino todos los reconocidos en los ordenamientos jurídicos. Sin embargo ${ }^{58}$, nunca llega a dar ejemplos sobre ello, pero sí plantea que, si se quieren garantizar, lo más importante es sustraerlos de la disponibilidad política y del mercado, con una formulación general y confiriéndolos por igual a todos. Aclara, además, que no debe incluirse en la noción de derechos fundamentales su rango constitucional, por cuanto existen Estados que no tienen Constituciones y otros que, teniéndolas, los incorporan mediante leyes ordinarias.

Entonces, de esta definición se entiende que todos los derechos que poseen los individuos son fundamentales sin interesar su reconocimiento constitucional. Esto es porque existen Estados que no tienen Constituciones y otros que, teniéndolas, incorporan los «derechos fundamentales» mediante leyes ordinarias. Baste con que

\footnotetext{
${ }^{54}$ Cfr. ChampeIL-Desplats, V., "Des « libertés publiques » aux «droits fondamentaux » : effets et enjeux d'un changement de dénomination" en Jus Politicum, $\mathrm{n}^{\circ} 5$, p. 2, disponible en http://juspoliticum.com/article/Des-libertes-publiques-aux-droits-fondamentaux-effets-et-enjeux-d-unchangement-de-denomination-290.html, consultado el 10 de diciembre de 2017.

${ }^{55}$ Cfr. Ferrajoli, L., Los fundamentos de los derechos fundamentales, Edición de Antonio CABO y Gerardo PISARELlO, Editorial Trotta, Madrid, 2001, p. 19.

${ }^{56}$ Cfr. FerRajoli, L., Los fundamentos... op. cit., p. 20.

57 Vid. Solozábal Echavarría, J.J., "Algunas cuestiones básicas de la teoría de los derechos fundamentales" en Revista Estudios Políticos (Nueva Época), No. 71, enero- marzo, Madrid, 1991, p.97.

${ }^{58}$ Cfr. FerRAJOLI, L., "Sobre los derechos fundamentales" en Revista Cuestiones Constitucionales, No. 15, Julio- diciembre, 2006, p. 117.
} 
existan en el ordenamiento jurídico con independencia de su base filosófica o ideológica ${ }^{59}$.

En esta misma línea, GUASTINI plantea que la expresión derechos fundamentales parece encerrar dos matices de significado. Desde una visión positivista, pueden entenderse como aquellos derechos que dan fundamento al sistema jurídico. Desde una concepción iusnaturalista, como aquellos que no requieren el fundamento del sistema jurídico, pero aún son fundamentales ${ }^{60}$.Por ello, es válido decir que su concepción depende de la ideología, los valores y los principios que consagren las constituciones ${ }^{61}$

Sin embargo, diversos pronunciamientos se sostienen en relación con la naturaleza de los derechos fundamentales. Por un lado, se conciben como derechos subjetivos de libertad, dirigidos al Estado; posición más aceptada al considerarlos como derechos subjetivos públicos ${ }^{62}$. Por otro lado, son normas objetivas de principio y decisiones axiológicas $^{63}$.

Un elemento importante que trasciende a la categoría «derechos fundamentales» es en qué se basa la fundamentalidad estos ${ }^{64}$. Pues, partiendo de la fundamentación ética axiológica, los derechos son fundamentales en tanto se vinculan estrechamente a la dignidad humana, son condicionantes de la misma ${ }^{65}$.

La dignidad humana tuvo su origen en la cuestión social y fue tratada por las Encíclicas papales de León XIII en $1891^{66}$. Tan antigua como se muestra, la dignidad está ligada a la racionalidad, la libertad y la autonomía. Ella tiene como sujeto a la persona humana, en sus dimensiones corporales y racionales, para asegurar su sociabilidad, responsabilidad y trascendencia ${ }^{67}$. Como principio - pilar fundamental ${ }^{68}$ - ha sido

\footnotetext{
${ }^{59}$ Vid. SOlOZÁBAL ECHAVARRÍA, J. J., “Algunas... op. cit., p.97.

${ }^{60}$ Cfr. GuASTINI, R., Estudios de teoría constitucional, UNAM, México, 2001, p. 221.

${ }^{61}$ Cfr. Bonavides, P., Curso... op. cit., p. 575.

${ }^{62}$ Vid. FerRAJOLI, L., Los fundamentos de los... op. cit., p. 19.

${ }^{63}$ Vid. BÖCKENFÖRDE, E.W., "Sobre la situación de la dogmática de los derechos fundamentales tras 40 años de Ley Fundamental" en Escritos sobre derechos fundamentales, BÖCKENFÖRDE E.W., REQUEJO J.L., e VillaVerde MENÉNDEZ I., Baden-Baden, Nomos, 1993, p. 95.

${ }^{64}$ Vid. BASTIDA, F. J., "El fundamento de los derechos fundamentales" en Revista Electrónica del Departamento de Derecho de la Universidad de La Rioja Redur, No. 3, La Rioja, 2005, pp. 41- 56.

${ }^{65}$ Vid. PACHECO G., Máximo: "Los derechos fundamentales... op. cit., p. 67.

${ }^{66}$ Cfr. Numerales 15, 19, 26 y 30 de la Carta Encíclica Rerum Novarum del Sumo Pontífice León XII "Sobre la situación de los obreros" disponible en https://w2.vatican.va/content/leoxiii/es/encyclicals/documents/hf_l-xiii_enc_15051891_rerum-novarum.html, consultado el 26 de febrero de 2018.

${ }^{67}$ Vid. LANDA, C., "Dignidad de la persona humana" en Revista Mexicana de Derecho Constitucional Cuestiones Constitucionales, No. 7, julio- diciembre, México, 2002, p.111 y ss.
} 
incorporada en los textos constitucionales, siendo un indicador del Estado Social de Derecho. La dignidad se convierte en condición de legitimación, no solo de los derechos fundamentales, sino de todo el ordenamiento jurídico. Por ello la fundamentalidad de los derechos parte de la propia dignidad humana ${ }^{69}$. En este sentido, el hombre necesita de condiciones mínimas de vida, tanto individual como colectivamente; y por supuesto, formas de participar en la vida social y política de su comunidad.

Otro elemento es el reconocimiento como fundamentales en fuentes legales de rango supremo $^{70}$. Es práctica extendida en las Constituciones modernas de dividir su articulado en derechos $\mathrm{y}$ derechos fundamentales ${ }^{71}$. Así parece que algunos son fundamentales y otros no. Por ello, la fundamentalidad, amén del reconocimiento depende también del alcance que se le otorgue a cada uno, de lo que se considere constituye dignidad humana; es decir, los que emanan del ser y no del deber ser ${ }^{72}$. Por último, la fundamentalidad de los derechos depende también de las garantías que se les atribuyan en el ordenamiento jurídico ${ }^{73}$. Cualquier derecho reconocido debe poseer un mecanismo de defensa ante posibles vulneraciones. Desde la Revolución francesa de 1789 al régimen constitucional se le asocian las garantías de los derechos fundamentales ${ }^{74}$.

De esta forma, los derechos fundamentales se erigen como derechos subjetivos. Es decir, son derechos que ostentan los individuos frente al Estado o frente a cualquier poder público ${ }^{75}$. Esto coloca en manos de sus titulares la posibilidad de exigir al Estado o a terceros, dichos derechos, amén de reclamar en caso de vulneración. Así, fungirán como derechos de defensa, prestacionales -jurídicas, materiales- y de participación ${ }^{76}$.

\footnotetext{
${ }^{68}$ Vid. Gonçalves Fernandes, B., Curso de Direito Constitucional, 3ra Ed., Editorial Lumen Juris, Rio do Janeiro, 2011, pp. 293 y ss.

${ }^{69}$ Vid. WOlfGang SaRlet, I., Dignidade da pessoa humana e direitos fundamentais na Constituiçao Federal de 1988, Nona Ediçao, Editora Livraria do advogado, Porto Alegre, 2011; DOS ANJOS MAGAlHÃes, Leslei L., O princípio da dignidade da pessoa humana e o direito à vida, Editora Saraiva, São Paulo, 2012; MAINHOFER, W., Estado de Derecho y dignidad humana, Euros Editores SRL, Buenos Aires, 2008.

${ }^{70}$ Cfr. AleXY, R., Teoría de los derechos fundamentales, Centro de Estudios Constitucionales, Madrid, 1993, p 503.

${ }^{71}$ Cfr. Artículos 14 y ss. de la Constitución española de 1978.

${ }^{72}$ Vid. BASTIDA, F. J., "¿Son los derechos sociales derechos fundamentales? Por una concepción normativa de la fundamentalidad de los derechos" en Derechos sociales y ponderación, Robert ALEXY, $2^{\text {a }}$ Ed., Fundación Coloquio Jurídico Europeo, Madrid, 2009, p. 109.

${ }^{73} \mathrm{Vid}$. SOlozÁbal ECHAVARRÍA, J. J., “Algunas cuestiones...op. cit., p. 91.

${ }^{74}$ Vid. Artículo 16 de la DDHC.

${ }^{75}$ DíEZ PicAzo, L.M: Sistema de derechos fundamentales, Editorial Thomson / Civitas, p. 35, disponible en http://www.redalyc/html/885/88500603, consultado el 27 de septiembre de 2017.

${ }^{76}$ Cfr. Ferreira MÉndez, G. y Gonet Branco, G., Curso de Direito Constitucional, $7^{\mathrm{a}}$ edição, Editora Saraiva, São Paulo, 2012, p. 460 y ss.
} 


\subsection{Características y clasificación de los derechos fundamentales}

Los derechos fundamentales poseen varias características. En primer lugar, su carácter universal $^{77}$, lo cual implica que todos los seres humanos por su condición de tal poseen estos derechos sin distinción; razón que le fue concedida por la Revolución francesa y su DDHC anexada a la Constitución de $1793^{78}$. Son además indisponibles -en el caso tanto del titular del derecho y no expropiables o limitables por otros sujetos comenzando por el Estado-, inalienables, inviolables, intransmisibles y personalísimos $^{79}$. Otros autores coinciden con dicha caracterización y agregan que son constitucionales, vitales, no absolutos y que se pueden ejercer frente al Estado ${ }^{80}$, e imprescriptibles, irrenunciables y limitables ${ }^{81}$.

Por último, los derechos fundamentales no se crean, sino que se declaran ${ }^{82}$. Esta es una característica esencial que coloca en manos de sus titulares la posibilidad de exigir frente al Estado, o frente a terceros, dichos derechos, amén de reclamar en caso de vulneración. Es decir, ya desde su reconocimiento el ciudadano posee una garantía primaria que abre paso a garantías secundarias de mayor envergadura. Dicho esto, los derechos fundamentales son considerados indispensables para las personas naturales y necesarios para asegurarles a todos una existencia digna, libre e igual ${ }^{83}$. A la par, los derechos fundamentales se instituyen como un elemento que caracteriza la forma de Estado, desde que se colocan como valores supremos en las Constituciones, en tanto, su disfrute pleno es la condición esencial para la subsistencia de un Estado democrático ${ }^{84}$. Un elemento nuclear en materia de derechos fundamentales es su clasificación. Debe tenerse en cuenta que, cada tipo de derecho fundamental corresponde a un momento histórico determinado donde confluyeron los intereses de las clases con afán de poder. En este punto, agruparlos parece ser una suerte de etiqueta para varios derechos, dejando fuera a otros.

\footnotetext{
${ }^{77}$ Vid. Gonçalves CARBalHo, K., Direito Constitucional didático, Editorial Del Rey, Belo Horizonte, 1999, p. 415.

${ }^{78}$ Cfr. Artículo 2 de la Constitución francesa de 1793 en Constitución francesa de 24 de junio de 1793. Disponible en http://www.ub.edu/ciudadania/hipertexto/evolucion/textos/francesas.htm, consultado el 14 de diciembre de 2016.

${ }^{79}$ Cfr. FerRajoli, L., Los fundamentos... op Cit., p. 32.

${ }^{80}$ Fuster, J. B., Derechos fundamentales y deberes cívicos de las personas, Comisión de Derechos Civiles, Puerto Rico, S/Año, p.23.

${ }^{81}$ Vid. Rebello Pinho, R. C,: Teoria Geral da Constituição e Direitos Fundamentais, $11^{\mathrm{a}}$ edição, Volume 17, Editora Saraiva, São Paulo, 2011, p. 97.

${ }^{82}$ Vid. CosTA, P., "Derechos fundamentales" en El Estado moderno en Europa. Instituciones y derecho, Maurizio FIORAVANTI (Coordinador), Editorial Trotta, Madrid, 2004, p. 52.

${ }^{83}$ Vid. Rebello PinHo, R. C., Teoria Geral... op. cit., p. 96.

${ }^{84}$ Rolla, Giancarlo: Derechos fundamentales, Estado democrático y justicia constitucional, Instituto de Investigaciones Jurídicas, Serie Ensayos Jurídicos No. 7, UNAM, México, 2002, p. 130.
} 
Ciertamente, la fundamentalidad de los derechos depende de varios elementos, desde el panorama histórico, social y cultural, hasta los intereses de cada Estado. Pero ello trasciende a su ubicación sistemática en las Constituciones y, por tanto, a las garantías que se le atribuyan a cada uno. Pero los derechos constitucionales no deben su fundamentalidad solamente a ello, en tanto se protegen por su importancia, y deben su jerarquía a la protección que se les otorga ${ }^{85}$. Ello reafirma que, de la forma en que sean determinados y configurados en las normas constitucionales, dependerán las garantías colocadas en manos de sus titulares. Siendo así, las clasificaciones varían, además, por los parámetros para su agrupación.

AlCALÁ GALIANO ${ }^{86}$, en una época tan temprana como 1843, clasificaba a los derechos en civiles, políticos y mixtos. GUASTINI ${ }^{87}$ por su parte, refiere que el contenido de los derechos fundamentales varía. Habrá entonces derechos de hacer por parte del Estado y derechos de abstención, o lo que es igual libertades públicas. Concluyendo así la tipificación en derechos positivos y negativos.

También otra distinción es la que se establece entre derechos de libertad, autonomía o defensa;derechos democráticos o de participación, y derechos sociales o prestacionales $^{88}$. Otras clasificaciones parten de su objeto y finalidad. De esta forma se dividen en derechos de libertad, derechos de igualdad y derechos políticos ${ }^{89}$.

PRIETO SANChÍZ ${ }^{90}$ realiza un estudio sobre la categorización de los derechos fundamentales donde alude a tres criterios clasificadores. Para este autor, por la finalidad y objeto los derechos serán diferenciados en derechos de libertad y derechos de igualdad. Pero, este autor también refiere dos criterios clasificadores más. Uno atendiendo al modo de ejercicio y contenido de la obligación -derechos de autonomía, de participación y prestacionales o de crédito-, y otro atendiendo al titular de los derechos, del hombre en general y específicos de los nacionales.

FERRAJOLI $^{91}$ por su parte, establece también una clasificación de los derechos fundamentales a partir de los diferentes estatus de las personas. Expone la existencia de

\footnotetext{
${ }^{85}$ Vid. Solozábal EchaVARRía, J.J., "Algunas cuestiones...op. cit., pp. 91 y 92.

${ }^{86}$ Alcalá Galiano, A., Lecciones de Derecho Político Constitucional, Imprenta D. I Boix, Madrid, 1843, p. 392.

${ }^{87}$ Vid. GUASTINI, R., Estudios de teoría constitucional, UNAM, México, 2001, p. 223.

${ }^{88}$ Cfr. SOLOZÁBAL ECHAVARRÍA, J.J., "Algunas cuestiones...op. cit., pp. 89 y ss.

${ }^{89}$ Vid. Nogueira AlCAlÁ, H., Teoría y dogmática de los derechos fundamentales, UNAM, Instituto de Investigaciones Jurídicas, Serie Doctrina Jurídica, No. 156, México, 2003, pp. 60 y ss.

${ }^{90}$ Cfr. PRIETo SAnChíz, Luis: Estudios sobre derechos fundamentales, 1ra Reimpresión, Editorial Debate, Madrid, 1994, p. 124.

${ }^{91}$ Cfr. FerRAJOLI, L., Los fundamentos... op. cit., pp. 294 y ss.
} 
derechos de las personas, donde los derechos fundamentales primarios coinciden con los derechos humanos; y los derechos fundamentales secundarios se colocan como derechos civiles. Además, para él existen los derechos del ciudadano. A éstos, les corresponden derechos públicos o sociales como derechos fundamentales primarios y, los derechos políticos como secundarios. De esta forma, los derechos fundamentales primarios son solo expectativas y los secundarios son, adicionalmente, poderes. Es decir, los derechos de la persona se manifiestan en derechos de libertad, que son expectativas negativas que se materializan en libertad de y para hacer; y en los derechos civiles -que representan el marco de la autonomía privada-. Los derechos del ciudadano entonces, son expectativas positivas donde se incluyen los derechos públicos y sociales; y los derechos políticos -que implican la autonomía política-. Solo comentar, para este autor la tipología de los derechos fundamentales radica en derechos de libertad, derechos sociales, derechos civiles y derechos políticos.

También los derechos fundamentales se distinguen por el bien jurídico protegido y la finalidad de su protección ${ }^{92}$. Así se tienen derechos personalísimos -0 derechos del hombre en general según PRIETO SANCHíZ-; derechos de sociedad, comunicación y participación que protegen a las personas en el ámbito de la sociedad civil; derechos políticos; derechos de la seguridad jurídica -referidos a la obtención de una protección individual a través de mecanismos comunitarios-; y derechos económicos, sociales y culturales.

Al igual, DíEz PICAZO ${ }^{93}$, por su función distingue entre derechos civiles, políticos y sociales; y por su estructura en derechos de defensa, de participación y de prestaciones. Otros autores ${ }^{94}$, si bien no realizan una distinción entre los tipos de derechos fundamentales, al enumerar los ejemplos definen como los clasifican.

Se pueden clasificar los derechos fundamentales también según los distinguen los Pactos Internacionales. Se tendrán entonces derechos civiles, derechos políticos,

\footnotetext{
${ }^{92}$ Vid. PeCEs-BARBA, G., Curso de derechos fundamentales. Teoría General, Universidad Carlos III, Madrid, 1995, pp. 453 y ss.

${ }^{93}$ Vid. DíEz PiCAZO, L. M. Sistema ... op. cit., pp. 43 y ss.

94 PISARello, G.,: Los derechos sociales, derechos republicanos... op. cit.; CARNOTA, Walter F.: Instituciones de Derecho Público, Editorial La Ley, Buenos Aires, 2005; ARANGO, Rodolfo: Los derechos sociales en Iberoamérica, estado de la cuestión y perspectivas de futuro, Cuadernos Electrónicos, No. 5.; FERnÁndEZ-MIRANDA CAMPOAMOR, A.,: "El Estado social” en Revista española de Derecho Constitucional, Año 21, No 69, Septiembre-Diciembre, 2003, pp. 139-180; NogUERA AlCALÁ, A., Los derechos sociales en las nuevas Constituciones latinoamericanas, Editorial Tirant lo Blanch, Valencia, 2010; Gordillo, A. et alias: Derechos Humanos, 5ta ed., Fundación de Derecho Administrativo, Buenos Aires, 2005; CARBonell, M. (Coordinador): Derechos fundamentales y Estado, UNAM, Instituto de Investigaciones Jurídicas, Serie Doctrina Jurídica, No 96, México, 2002.
} 
derechos sociales, derechos culturales, derechos económicos y derechos de solidaridad $^{95}$.

No existe una clasificación uniforme, pero la más acertada parece ser la que los divide por generaciones de derechos, haciendo referencia a los momentos históricos que dieron lugar a su reconocimiento y que es comúnmente conocida. De esta forma serán derechos de primera generación los civiles y políticos (libertades); de segunda, los económicos, sociales y culturales (igualdad) y los de tercera serían los colectivos (solidaridad).Ello no significa supremacía entre unos y otros, al contrario, implica interrelación y complemento.

\subsection{Elementos de los derechos fundamentales}

Al definir el concepto de derechos fundamentales se estableció que son derechos subjetivos. Ello implica un conjunto de facultades que corresponden al individuo y que éste puede ejercitar para hacer efectivos los derechos que las normas legales le reconocen ${ }^{96}$. Pero sus funciones pueden observarse en otras dos dimensiones. Los derechos fundamentales se colocan como principios objetivos de un ordenamiento jurídico. Esto indica que el legislador tiene la obligación de dictar las normas necesarias para la preservación de estos derechos en las relaciones individuales en el seno de la sociedad $^{97}$. De tal suerte, también se erigen como garantías institucionales consideradas como elementos arquitecturales indispensables para el orden constitucional ${ }^{98}$.

En definitiva, su principal función y naturaleza jurídica estriba en ser derechos públicos subjetivos, en tanto sus titulares pueden exigir su efectivo cumplimiento. Por ello, se hace indispensable abordar cuestiones generales sobre la teoría de los derechos subjetivos para delimitar los elementos de los derechos fundamentales.

Si de evolución del concepto de derecho subjetivo se refiere, lo primero que salta a la vista es que su origen se encuentra ligado a una concepción del mundo; esencialmente el individualismo. Deriva de ello la concepción clásica del derecho subjetivo, como un poder del individuo ${ }^{99}$. En este sentido, el derecho subjetivo es un atributo jurídico

\footnotetext{
95 Vid. Declaración Universal de Derechos Humanos, Pacto de los Derechos Civiles y Políticos, Pacto Internacional de Derechos Económicos, Sociales y Culturales.

96 Cfr. Ossorio, M.: Diccionario de Ciencias Jurídicas, Políticas y Sociales, 1ra Ed. Electrónica, Editorial Datascán SA, Guatemala, S/Año, p. 312.

${ }^{97}$ Cfr. Rubio LloRente, F.., La forma ... op. cit., p. 991.

${ }^{98}$ Cfr. RuBio Llorente, F., La forma... op. cit., p. 993.

99 Vid. DíAz CRuZ, M., "La Doctrina del derecho subjetivo" en Revista General de Legislación y Jurisprudencia, mayo, Instituto Editorial Reus, Madrid, 1947, p. 5.
} 
individual que nace cuando el individuo logra la consagración política mediante las declaraciones de derechos ${ }^{100}$.

Durante los siglos XVII y XVIII, según la noción iusnaturalista, los derechos subjetivos son innatos al individuo y anteriores a las leyes positivas. Esta idea de los derechos subjetivos como un interés jurídicamente protegido, cuya satisfacción queda encomendada a su titular, no nació como instrumento conceptual para la interpretación del derecho positivo, sino como soporte técnico de los derechos naturales ${ }^{101}$. Originalmente sirvió para designar las libertades de naturaleza supra positiva para sustraer determinados ámbitos de libertad a la capacidad de regulación del Estado. Posteriormente, con la influencia del positivismo, se comenzó a utilizar para designar las facultades otorgadas a los individuos por la legalidad ordinaria. En esta línea planteó DuGuiT $^{102}$ que los derechos subjetivos son el poder que corresponde a una voluntad de imponerse como tal a una o varias voluntades, cuando quiere una cosa que no está prohibida en ley.

En función de esto, existen un conjunto de teorías en torno a los derechos subjetivos. Una primera, denominada de la voluntad y defendida por Savigny ${ }^{103}$ plantea que los derechos subjetivos son un poder atribuido a la voluntad de los sujetos, que se manifiesta en el nacimiento o desaparición de derechos propios y exigiendo a otros sujetos algún comportamiento previsto en la norma que ampara el propio derecho ${ }^{104}$. Por otro lado, se encuentra la teoría del interés defendida por IHERING, que plantea que los derechos subjetivos son un interés jurídicamente protegido cuya efectividad depende de la iniciativa del propio titular. Para ello deriva en el interés del sujeto y en el procedimiento jurídico de defensa del derecho.

Por último, está la teoría defendida por $\operatorname{KELSEN}^{105}$; la teoría de la posición jurídica, donde la esencia del derecho subjetivo se encuentra en el hecho de que una norma otorgue al individuo al poder jurídico de reclamar, mediante una acción, por el incumplimiento de la obligación.

\footnotetext{
${ }^{100}$ Vid. DíAz CruZ, M., "La Doctrina del... op. cit., p. 11.

${ }^{101}$ Cfr. Diez PICAZO, L.M., Sistema de derechos... op cit.

${ }^{102}$ Cfr. Duguit, L., Las transformaciones generales del derecho positivo desde el Código de Napoleón, CARLos G. PoSADA (trad.), 2da Ed., Francisco Beltrán, Librería Española y Extranjera, Madrid, S/Año, p. 26.

${ }^{103}$ Vid. FerRAJOLI, L., "Sobre los derechos fundamentales" ... op. cit., p. 72.

${ }^{104}$ Vid. CASTRO CID, B., de, Manual de Teoría del Derecho, vlex, 20014, p. 1.

${ }^{105}$ Cfr. Kelsen, H., Teoría pura del derecho, 4ta Ed., 9na reimpresión, Editorial Eudeba, Buenos Aires, 2009, p. 100.
} 
De tal suerte, la noción de los derechos subjetivos juega hoy un papel fundamental en tanto la sociedad es individualista y habrá de pensarse el derecho en función del individuo $^{106}$. Así es que el derecho subjetivo en sentido estricto es la norma positiva, el derecho objetivo en sí mismo; la posibilidad de poner en marcha el mecanismo coercitivo del Estado. Desde el punto de vista del sujeto es la posibilidad de hacer o de omitir lícitamente algo ${ }^{107}$, tanto en el ámbito privado como en el público ${ }^{108}$. En esencia, los derechos subjetivos son una posibilidad atribuida al individuo para que ponga en movimiento la aplicación una norma jurídica en su propio interés ${ }^{109}$.

Al tenerse a los derechos fundamentales como derechos subjetivos, lo primero que se puede afirmar es que aquellos hacen nacer para sus titulares un conjunto de prerrogativas en función de su efectivo ejercicio. En conexión con esto, ALEXY ${ }^{110}$ plantea que los derechos fundamentales como derechos subjetivos plantean tres cuestiones fundamentales «normativas, empíricas y analíticas». Empero, trascienden aquellas en el marco analítico pues implican un sistema de posiciones jurídicas fundamentales: el derecho a algo. Tal puede consolidarse en derechos a acciones negativas y derechos a acciones positivas. Por ello, siempre que alguien posee un derecho fundamental, existe una norma válida de derecho fundamental que le otorga este derecho $^{111}$. Es decir, no vale cuando existen normas de derecho fundamental que no otorgan ningún derecho subjetivo.

Desde el punto de vista teórico estructural, las normas de derecho fundamental pueden identificarse como normas que confieren derechos subjetivos o que obligan al Estado solo objetivamente; normas vinculantes o no vinculantes y normas que pueden ser principios o reglas $^{112}$.

Ahora bien, diversos elementos conforman la teoría de los derechos subjetivos, lo cual se traslada a los derechos fundamentales. El primero es el referido a la titularidad del

\footnotetext{
${ }^{106}$ Cfr. VILLEY, Michel y VILLET, M., "L'idée du droit subjectif et les sistémes juridiques romains" en Revue historique de droit français et étranger, Quatriéme sêrie, Vol. 24, 1946- 1947, p. 201.

107 Vid. Vallado Berrón, F. E., El derecho subjetivo disponible en http://www.derecho.unma.mx, consultado el 15 de diciembre de 2017.

${ }^{108}$ Cfr. JellineCK, J., Sistema de Derecho Público Subjetivo, traducción italiana de Gaetano Vitagliano, Societa Editrice Libraria, Milano, 1912, pp. 57 y ss.; MAESTRO, Gonzalo: "Los derechos públicos subjetivos en la historia del constitucionalismo español del siglo XIX" en Revista de Derecho Político, No. 41, 1996, p. 129.

109 Vid. García de EntarRía, E., "Sobre los derechos públicos subjetivos" en Revista Española de Derecho Administrativo, No. 6, Madrid, 1975, p. 427.

${ }^{110}$ Cfr. AlEXY, R., Teoría de los derechos fundamentales, Centro de Estudios Constitucionales, Madrid, 1993, p. 173.

${ }^{111}$ Cfr. AlEXY, R., Teoría ... op. cit., p. 47.

${ }^{112}$ Cfr. AleXY, R.,: Teoría... op. cit., p. 484.
} 
derecho, que en resumen lo poseen todas las personas que reconozca el propio derecho en cuestión. Derivado de ello, se requiere de la determinación del contenido del derecho y de sus límites. En este caso, depende de cada derecho en concreto. Por último, es necesario establecer entonces que garantías posee ese derecho para su defensa, lo que, en definitiva, completa el concepto de derecho fundamental como derecho subjetivo. Sin dejar de lado ningún elemento, se fijarán en virtud de un orden metodológico cuatro pilares fundamentales: la titularidad de los derechos fundamentales, el contenido de los mismos, sus límites y sus garantías.

En cuanto al elemento subjetivo de los derechos fundamentales, la titularidad de estos derechos está destinada a los ciudadanos y su destinatario es el poder público ${ }^{113}$. En principio, todas las personas naturales son titulares de los derechos fundamentales, como bien lo indica la característica de universalidad de los derechos humanos, aunque influyen las categorías de nacionalidad-ciudadanía ${ }^{114}$. Los titulares requieren de una cierta capacidad jurídica -jusfundamental- que refleja la abstracta capacidad de los individuos para ser sujetos de imputación de derechos y obligaciones fundamentales, para ser titular de ellos. A partir de esto es que se posee titularidad y se es beneficiario de los derechos ${ }^{115}$.

De aquí deriva lo relativo al tratamiento a los extranjeros y apátridas. Partiendo del citado principio de universalidad serán titulares estos sujetos, mas, cada Estado definirá los elementos para hacer efectivos los derechos fundamentales ${ }^{116}$, partiendo de los criterios de residencia permanente o no y de ciudadanía. Por ejemplo, en el caso de los derechos de participación política se requiere ser ciudadano. En otras palabras, los titulares de los derechos fundamentales son los habitantes de un Estado, y de forma excepcional otros sujetos con un punto de conexión suficiente para regirse por las normas nacionales.

De igual manera aparece el caso de las restricciones de la capacidad de ejercicio de los derechos fundamentales a los menores y a los incapaces. En este caso, si bien son

\footnotetext{
${ }^{113}$ Cfr. GómEZ Montoro, A. J., "La titularidad de los derechos fundamentales por personas jurídicas (análisis de la jurisprudencia del tribunal constitucional español)" en Revista Cuestiones Constitucionales, No. 2, enero-junio, 2000, p. 25.

${ }^{114}$ Vid. LÓPEZ GuERRA, L., et al.: Derecho Constitucional, Vol. I, Editorial Tirant lo Blanch, Valencia, 1997, p. 156.

${ }^{115}$ Cfr.BASTIDA, F. J. et alias, Teoría General... op. cit., p. 71.

116 Vid. Wolfgang SARLET I., A eficácia dos direitos fundamentais. Uma teoria geral dos direitos fundamentais na perspectiva constitucional, $10^{\mathrm{a}}$ edição, Editoria Livraria do Advocado, Porto Alegre, 2009 , pp. 211 y ss.
} 
titulares del derecho, su ejercicio solo podrán realizarlo en tanto su tutor legal así lo autorice $^{117}$.

En otro sentido, las personas jurídicas también podrán ser sujetos de los derechos fundamentales. Una afirmación categórica sobre ello requiere de un análisis profundo de cada derecho en particular y la determinación de su ejercicio por parte de estos sujetos. Sin embargo, la solución la tienen las Constituciones de cada Estado, así como la interpretación del contenido y alcance de cada derecho en especial ${ }^{118}$. Pero parece ser que la respuesta más razonable es plantear que todas las personas jurídicas son sujetos de derechos fundamentales en tanto éstos no sean propios o exclusivos de los individuos, por su propia naturaleza ${ }^{119}$. Su titularidad solo se reconoce para el caso de algunos derechos ${ }^{120}$.

También habrá de analizarse si son personas del ámbito privado o del ámbito público. En este sentido, la respuesta parece ser clara. Si son públicas no serán sujeto de derechos fundamentales, en tanto no poseen derechos sino competencias y atribuciones. Mas, si actúa bajo un régimen jurídico privado, la cuestión es diferente y puede perfectamente ser sujeto de derechos fundamentales ${ }^{121}$.

Frente a esta titularidad de los derechos fundamentales se encuentra el Estado, derivado de la propia concepción de los derechos fundamentales como derechos subjetivos. No obstante, el resto de los individuos se encuentran en una posición idéntica. El primero en tanto es quien está obligado a respetar, fomentar y garantizar el ejercicio de todos los derechos fundamentales. Los segundos, por cuanto no deben interferir en los derechos de otras personas «límites al ejercicio de los derechos».

Por su parte, en cuanto al contenido de los derechos fundamentales, depende esencialmente de lo que cada Estado establezca en su ordenamiento jurídico interno. Igualmente difiere según el derecho del que se trate. En este sentido, baste decir que el

\footnotetext{
${ }^{117}$ Cfr. RUBio LloRente, F., La forma ... op. cit., pp. 1011 y ss.

118 Vid. CARbonell, M., "Derechos Humanos en la Constitución mexicana" en Derechos Humanos en la Constitución: Comentarios de Jurisprudencia Constitucional e Interamericana, T. I, MAC-GREGOR PoISOT E.F., et alias (Coordinadores), UNAM, Instituto de Investigaciones Jurídicas Konrad Adenauer Stiftung, Programa Estado de Derecho para Latinoamérica, México, 2013, pp. 33 y ss.

${ }^{119}$ V. g.: igualdad, inviolabilidad del domicilio, libertad de asociación, derecho a la información, derecho de petición, tutela judicial efectiva, derechos tributarios, etc.

${ }^{120}$ Cfr. GómeZ Montoro, Ángel J., "La titularidad de los derechos fundamentales por personas jurídicas (análisis de la jurisprudencia del Tribunal Constitucional español)" en Revista Mexicana de Derecho Constitucional, Cuestiones Constitucionales, No. 39, enero-junio, 2018, p. 2.

${ }^{121} \mathrm{Cfr}$. GÓMEZ MONTORO, A.J., "La titularidad de los derechos fundamentales por personas jurídicas: un intento de fundamentación" en La democracia constitucional. Estudios en homenaje al profesor Francisco Rubio Llorente, T.I, CEPC/ UCM/ Tribunal Constitucional, Madrid, 2002, p. 437.
} 
contenido de los derechos fundamentales posee un núcleo duro, su esencia, indisponible por el legislador o el juez, que será establecido en función de cada sociedad en específico. El contenido del derecho se manifiesta en el conjunto de facultades que tiene el titular del derecho. Se desprende de la naturaleza del derecho en sí mismo y de lo que el legislador y el juez determinen significa en sí ese derecho. Estas «facultades» que conforman el núcleo del derecho en cuestión serán concretadas por los propios límites que se determinen posee el derecho.Así el contenido esencial incluye el resto de los elementos que configuran a los derechos fundamentales: el titular, el objeto del derecho y los límites internos.

De tal suerte, para determinar el contenido de los derechos hay un conjunto de limitaciones a los mismos. Ya desde el artículo 4 de la DDHC se establece un límite a los derechos ${ }^{122}$.

El último elemento que configura los derechos fundamentales es el conjunto de mecanismos de defensa que posee frente a vulneraciones. Sin tener espacio para un análisis pormenorizado de los mismos, y por no ser parte del objeto de esta investigación, solo se hará mención a ellos. La primera garantía es el propio reconocimiento del derecho. Otras garantías son el recurso de amparo, el habeas corpus, la revisión judicial y la acción de inconstitucionalidad ${ }^{123}$. Igualmente, existen otros mecanismos de defensa de los derechos fundamentales en el ámbito penal con la tipificación de delitos cuyos bienes jurídicos protegidos son derechos fundamentales.

\section{Bibliografía}

AleXy, R., Teoría de los derechos fundamentales, Centro de Estudios Constitucionales, Madrid, 1993.

AleXY, R., "Law, morality and the existence of human rights" en Ratio Iuris, Vol. 25, No. 1, marzo de 2012.

AlEXY, R., "The existence of human rights" in Law, Science, Technology, Plenary lectures presented at the $25^{\text {th }}$ World Congress of the International Association for Philosophy of Law and Social Philosophy, Frankfurt am Main, 2011.

\footnotetext{
${ }^{122}$ Artículo 4 de la DDHC.

${ }^{123} C f r$. FIX-ZAMUdio, H "Los derechos humanos y su protección jurídica y procesal en Latinoamérica" en Derechos humanos. Memorias al IV Congreso Nacional de Derecho Constitucional, T.: III, VALADÉs D. y GuTIÉRREZ RIVAS R. (Coordinadores), UNAM, México, 2001, pp. 3 y ss.
} 
ARrieta SiLVA, E., "Hacia la autonomía plena de los derechos humanos como disciplina jurídica" en Derecho Humanos. Memorias del IV Congreso Nacional de Derecho Constitucional, T.: III, VALADÉS D., y GUTIÉRREZ RIVAS, R., (Coordinadores), UNAM, México, 2001.

BAdeni, G., Tratado de Derecho Constitucional, Tomo I, 2da Ed., Editorial La Ley, Buenos Aires, 2006.

BAstidA, F. J., "El fundamento de los derechos fundamentales" en Revista Redur, No. 3, 2005.

BAyÓn Chacón, G. y PÉREz BotiJa, E., Teoría general de los derechos fundamentales en la Constitución española de 1978, Editorial Tecnos, Madrid, 2004.

Bonavides, P., Curso de Direito Constitucional, 15 Ed. Gráfica Paym, Brasil, 1999. Curso de Direito Constitucional, 31 a edição, Malheiros Editores, São Paulo, 2016.

Bonavides, P., Teoría Constitucional de Democracia participativa, Malheiros Editores LTDA, São Paulo, 2001.

BurgoA O. I., Las garantías individuales, 40ª Ed., Editorial Porrúa, México, 2008.

Carbonell, M., "Derechos humanos en la Constitución mexicana" en Derechos Humanos en la Constitución. Comentarios de Jurisprudencia constitucional e Interamericana, FERRER MAC-GREGOR POISOT E., et alias (Coordinador), T.: I, UNAM, Instituto de Investigaciones Jurídicas Konrad Adenauer Stiftung, México, 2013.

Carnota, W F., Instituciones de Derecho Público, Editorial La Ley, Buenos Aires, 2005.

CARPIZO, J., Derechos Humanos y ombudsman, 2da Ed., Editorial Porrúa/UNAM, Instituto de Investigaciones Jurídicas, 1998.

Carpizo, J. y Madrazo, J., Derecho Constitucional, UNAM, México, 1991.

Carvalho Ramos, A., Teoria geral dos direitos humanos na ordem internacional, Editora Saraiva, São Paulo, 2012.

CASAdo Filho, N., Direitos humanos e fundamentais, Editora Saraiva, São Paulo, 2012. 
CAstán Tobeñas, J., Los derechos humanos, Editorial Reus, Madrid, 1978.

CAstilho, R., Direitos humanos, Editora Saraiva, São Paulo, 2011.

CASTRO DE CID, B., de: "Derecho subjetivo y deber jurídico" en Manual de teoría del Estado, Editorial Jurídica de Internet vLex, 2004.

Cena EgañA, J. L., "Garantías constitucionales en el estado social de derecho" en Revista Chilena de Derecho, Vol. 10, 1983.

Champeil-Desplats, V., "Des « libertés publiques » aux " droits fondamentaux: effets et enjeux d'un changement de dénomination" en Jus Politicum, ${ }^{\circ} 5$ disponible en http://juspoliticum.com/article/Des-libertes-publiques-aux-droits-fondamentaux-effetset-enjeux-d-un-changement-de-denomination-290.html,consultado el 8 de diciembre de 2017.

ChAMPEIL-DesPlats, V., "La théorie générale de l'État est aussi une théorie des libertés fondamentales" en Jus Politicum, No. 8 disponible en http://juspoliticum.com/article/La-theorie-generale-de-1-Etat-est-aussi-une-theorie-deslibertes-fondamentales-537.html, consultado el 7 de diciembre de 2017.

Costa, P., "Derechos fundamentales" en El Estado moderno en Europa. Instituciones y derecho, Maurizio FiORAVANTI (Coordinador), Editorial Trotta, Madrid, 2004.

Da Cunha Júnior, D., Curso de Direito Constitucional, $5^{\text {a }}$ edição, Editora Juspodium, Salvador- Bahia, 2011.

De CABo Martín, C., Estudios sobre el Estado Constitucional y el Constitucionalismo del Estado de Derecho, UNAM, México, 1997.

De la Madrid H. M., Constitución, Estado de derecho y democracia, UNAM, México, 2004.

De Hostos, J. M., Lecciones de Derecho Constitucional, Sociedad de Ediciones Literarias y Artísticas, París, 1908.

DíAz Revorio, F. J., "Derechos Humanos y deberes fundamentales. Sobre el concepto de deber constitucional y deberes en la Constitución Española de 1978" en Revista Del Instituto de Ciencias Jurídicas de Puebla, Año V, No. 28, México. 
Duguit, L., Traité de Droit Constitutionnel, Tome Cinqueme et dernier, Duxième Edition, Ancienne Librairie Fontemoing \& gie Editeurs, Paris, 1923,

FERnÁndeZ, E., Teoría de la Justicia y Derechos Humanos, Editorial Debate, Primera Reimpresión, Madrid, 1987.

FerRAJOLI, L., "Las garantías constitucionales de los derechos fundamentales" en Revista Doxa, Cuadernos de Filosofia del Derecho, No. 29, 2006.

FERrAjoli, L., Los fundamentos de los derechos fundamentales, CABO A. y PISARELlO G. (EDS), Editorial Trotta, Madrid, 2001.

FERRAJOLI, L., "Sobre los derechos fundamentales" en Teoría del Neo constitucionalismo. Ensayos escogidos, CARBOnEll M., (ED), Instituto de Investigaciones Jurídicas, UNAM, Editorial Trotta, Madrid, 2007.

Ferreira Méndez, G. y Gonet Branco, G., Curso de Direito Constitucional, $7^{\text {a }}$ edição, Editora Saraiva, São Paulo, 2012.

FIX- ZAMUDIO, H., "La evolución el derecho internacional de los derechos humanos en las Constituciones latinoamericanas" en Estudios Básicos de Derechos Humanos, T. II, Cançado Trinidade, A. y González Volio, L., IIDH, San José, 1995.

FIX- ZAMUdIO, H., "Los derechos humanos y su protección jurídica y procesal en Latinoamérica" en Derechos humanos. Memorias al IV Congreso Nacional de Derecho Constitucional, T.: III, VALADÉs D., y GUTIÉRREZ RIVAS R., (Coordinadores), UNAM, México, 2001.

FIX- ZAmUdio, H., Los tribunales constitucionales y los derechos humanos, UNAM, México, 1980.

Flores SAlgado, L. L., Temas actuales de los derechos humanos de última generación, Benemérita Universidad Autónoma de Puebla, México, 2005.

Fuster, J. B., Derechos fundamentales y deberes cívicos de las personas, Comisión de Derechos Civiles, Estado Libre Asociado de Puerto Rico, San Juan, 1999.

García Becerra, J. A., Teoría de los derechos humanos, 1ra Ed., Universidad Autónoma de Sinaloa, México, 1991. 
García Belaunde, D., (Coordinador): Constitucionalismo y derechos humanos (Ponencias peruanas al VII Congreso Iberoamericano de Derecho Constitucional), Editora Jurídica Grijley, Lima, 2002.

Gómez Montoro, Á J., "La titularidad de los derechos fundamentales por personas jurídicas: un intento de fundamentación" en La democracia constitucional. Estudios en homenaje al profesor Francisco Rubio Llorente, T.I, CEPC/ UCM/ Tribunal Constitucional, Madrid, 2002.

Gonçalves Carbalho, K., Direito Constitucional didático, Editorial Del Rey, Belo Horizonte, 1999.

Gonçalves Fernandes, B., Curso de Direito Constitucional, 3ra Ed., Editorial Lumen Juris, Rio do Janeiro, 2011.

Gonçalves Ferreira Filho, M., Curso de Direito Constitucional, 38 Ed., Editorial Saraiva, São Paulo, 2012.

GonZÁlez PiLOTO, L. M., "El amparo constitucional como garantía de los derechos" en Revista Justicia y Derecho, Año 14, no. 26, junio de 2016.

Gordillo, A., et alias, Derechos Humanos, 5ta ed., Fundación de Derecho Administrativo, Buenos Aires, 2005.

GUASTINI, R., Estudios de teoría constitucional, UNAM, México, 2001.

Konder Comparato, F., A Afirmação histórica dos direitos humanos, 7ma Ed., Editorial Saraiva, São Paulo, 2010.

LENZA, P., Direito Constitucional esquematizado, $17^{\text {a }}$ edição, Editora Saraiva, São Paulo, 2012.

Lester dos Anjos Magalhães, L., O princípio da dignidade da pessoa humana e o direito à vida, Editora Saraiva, São Paulo, 2012

LÓPEz GuerRA, L. et alias, Derecho Constitucional, Vol. I, 3ra Ed., Editorial Tirant lo Blanch, Valencia, 1997.

MarÁn NAVARro, S. A., "La protección de los derechos humanos sociales en la supervisión del gasto público del gobierno mexicano" en Ciencia Jurídica, No. 8, Año 
4, Universidad de Guanajuato, 2015, disponible en http://repositorio.upacifico.edu.ec/bitstream/40000/129/17TDC-UPAC-19093.pdf, consultado el 4 de enero de 2016.

Martins Filho, I. G., "Direitos Fundamentais" en Tratado de Direito Constitucional, T. I, Colectivo DE AUtORES, $2^{\text {a }}$ edição, Editora Saraiva, 2012.

Masson, N., Manual de Direito constitucional, $2^{\mathrm{a}}$ edição, Editora Ius Podium, 2014.

Monroy Cabra, M. G., Los derechos humanos, Editorial Temis, Bogotá, 1980.

NikKen, P., "El concepto de derechos humanos" en Estudios Básicos de Derechos Humanos, T. I, Rodolfo Cerdas CRUZ y Rafael Nieto LoAizA, IIDH, San José, 1994.

Nogueira Alcalá, H., Teoría y dogmática de los derechos fundamentales, UNAM, Instituto de Investigaciones Jurídicas, Serie Doctrina Jurídica, No. 156, México, 2003.

PACHECO G., M., "Los derechos fundamentales de la persona humana" en Estudios básicos de derechos humanos, T.: II, Kenneth Anderson et alias, IIDH, San José, 1995.

Peces- BARBA, G., Curso de derechos fundamentales. Teoría General, Universidad Carlos III, Madrid, 1995.

PeCeS- BARBA, G., Derechos y derechos fundamentales, Centro de Estudios Constitucionales, Madrid, 1993.

Pereira de Souza Neto, C. y Sarmento, D., Direito Constitucional. Teoria, história e métodos de trabalho, Editora Fórum, Belo Horizonte, 2012.

Pérez Luño, A. E., Derechos Humanos, Estado de Derecho y Constitución, 5ta Ed., Editorial Tecnos, Madrid, 1995.

PÉrez Luño, A. E., Derechos Humanos. Estado de Derecho y Constitución, 7ma Ed., Editorial Tecnos, Madrid, 2001.

Piovesan, F., Temas de direitos humanos, $5^{\mathrm{a}}$ edição, Editora Saraiva, 2012.

PRIETO SANCHÍz, L., Estudios sobre derechos fundamentales, 1ra Reimpresión, Editorial Debate, Madrid, 1994. 
Rebello Pinho, R. C., Teoría Geral da Constituicão e Direitos Fundamentais, Vol. 17, $11^{a}$ edição, Editora Saraiva, São Paulo, 2011.

SCHMIDT, C., Teoría de la Constitución, $4^{\mathrm{a}}$ reimpresión, Editorial Alianza, Salamanca, 2003.

Soberanes Fernández, J. L., Sobre el origen de las declaraciones de derechos humanos, UNAM, Instituto de Investigaciones Jurídicas, México, 2009.

SOlozÁBAl ECHAVARRÍA, J. J., “Algunas cuestiones básicas de la teoría de los derechos fundamentales” en Revista Estudios Políticos (Nueva Época), No. 71, enero- marzo, 1991.

Tacio de Oliveira, R., Manual de Direito Constitucional, Editorial Rua Teixeira Magalhaes, Belo Horizonte, 2000.

TORRADO, F. R., Los derechos humanos en el sistema político cubano, Editorial Ciencias Sociales, La Habana, 2003.

Van Holthe, L., Direito Constitucional, 6ta Ed., Editora Podium, Brasil, 2010.

\section{OTROS DOCUMENTOS}

Documentos de Derechos Humanos disponible en http://ap.ohchr.org/documents/sdpage_s.aspx $? \mathrm{~b}=1 \& \mathrm{c}=47 \& \mathrm{t}=11$, consultado el $5 \mathrm{de}$ septiembre de 2017.

\section{NORMAS EXTRANJERAS O DE CARÁCTER INTERNACIONAL}

Pacto Internacional de Derechos Económicos, Sociales y Culturales de 1948. CoMISIÓN Nacional de Derechos Humanos: Pacto Internacional de Derechos Económicos, Sociales y Culturales y su Protocolo Facultativo, 1ra Edición, México, 2012.

Convención Internacional sobre la Eliminación de todos las Formas de Discriminación Racial adoptada por la Asamblea General de las Naciones Unidas el 21 de diciembre de 1965.

Convención sobre la Eliminación de todas las formas de discriminación contra la mujer adoptado por la Asamblea General de Naciones Unidas el 18 de diciembre de 1979. 
Convención sobre los derechos del niño adoptada por la Asamblea General de las Naciones Unidas el 20 de noviembre de 1989.

Declaración Americana de los Derechos y Deberes del Hombre de 1948, disponible en https://www.oas.org/dil/esp/Declaraci\%C3\%B3n_Americana_de_los_Derechos_y_Deb eres_del_Hombre_1948.pdf, consultado el 16 de enero de 2017.

Declaración Universal de Derechos Humanos adoptado por la Asamblea General de las Naciones Unidas en su Resolución 217 A (III), el 10 de diciembre de 1948 en París.

Declaración de México, Carta Socio laboral Latinoamericana, AsOCIACIÓN LATINOAMERICANA DE ABOGADOS LABORALISTAS, disponible en http://www.sintraisa.org/images/pdf/carta_sociolaboral.pdf, consultado el 16 de enero de 2017.

African (Banjul) Charter on Human and Peoples' Rights, (Adopted 27 June 1981, OAU Doc. CAB/LEG/67/3 rev. 5, 21 I.L.M. 58 (1982), entered into force 21 October 1986). 